\title{
Accelerated weathering studies on the bioplastic, poly(3-hydroxybutyrate-co-3-
} hydroxyvalerate)

\author{
Liqing Wei, Armando G. McDonald* \\ Renewable Materials Program, Department of Forest, Rangeland and Fire Sciences, University \\ of Idaho, 875 Perimeter Drive MS1132, Moscow, Idaho 83844, USA. \\ *Corresponding author: Tel.: +1 208885 9454; Fax: +1 2088856226. \\ E-mail address: armandm@uidaho.edu (A.G. McDonald).
}

\begin{abstract}
The effect of accelerated weathering exposure time on the bioplastic, poly(3-hydroxybutyrateco-3-hydroxyvalerate) (PHBV) was studied. The chemical structure and thermophysical property changes of solvent cast PHBV films were examined by a combination of optical microscopy, size exclusion chromatography, FTIR and ${ }^{1} \mathrm{H}-\mathrm{NMR}$ spectroscopies, tensile testing, and differential scanning calorimetry (DSC). The exposed PHBV surfaces experienced surface crazing upon weathering. The molar mass of weathered PHBV was shown to decrease due to chain scission which was dominant over the crosslinking reaction mechanism, and compositional analysis showed the polymer degradation was non-random between the hydroxybutyratehydroxyvalerate units. The degree of crystallinity for PHBV was shown to increase significantly (by 20\%) upon weathering. Tensile tests showed that the weathered PHBV exhibited reduced ultimate strength and elongation to break, while the Young's modulus increased ascribing to an increase in crystallinity. Different degradation mechanisms (Norrish I/II, radical initiation, crosslinking, and hydrolysis) of PHBV are proposed and confirmed based on the experimental
\end{abstract}


findings. This study provides degradation insight for PHBV exposed to both UV radiation and moisture.

Keywords: PHBV; Bioplastic; Accelerated weathering; Photodegradation; Thermophysical property

\section{Introduction}

Driven by the awareness of developing a sustainable society, biobased plastics (e.g., polyhydroxyalkanoate (PHA), polylactic acid (PLA), polycaprolactone (PCL), and lignocellulosic derived materials) have gained considerable attention over the past decades due to their renewability [1-11]. Of the microbial biosynthesied PHA bioplastic family, poly(3hydroxybutyrate) (PHB) and poly(3-hydroxybutyrate-co-3-hydroxyvalerate) (PHBV) are the two most common types produced as bacterial intracellular granules [6,12]. Furthermore, PHA can also be biodegraded readily by microbial hydrolytic enzymes and therefore will not accumulate in the environment [13-15]. The ester bonds (-COO-) of these above mentioned bioplastics are very susceptible to hydrolysis during exposure to various natural environments such as marine and waste environment $[6,15,16]$.

Most of the degradation studies on PHA have focused on the biodegradation behavior of PHB and PHBV when exposed to water [17], soil [13, 18, 19], waste compost [20], and enzymes [14, 21]. These reports show that water plays a key factor during the whole biodegradation process. However, only a few studies have been conducted on weathering exposure, notably UV-A [22, 23] and UV-B [24] degradation of PHB and photodegradation of PHBV [25]. For PHB, there are many competing mechanisms (radical initiation, crosslinking, and Norrish types I/II) of 
photodegradation to UV radiation [22]; whereas the degradation mechanism of aliphatic polyesters PLA and PCL mainly follow Norrish Type II reaction [9, 25]. Due to polymer chain cleavage during photodegradation, the molar mass, crystal structure, crystallinity, and thermal/mechanical properties are all influenced $[9,26]$.

Weathering of traditional plastics such as high density polyethylene (HDPE) and polypropylene (PP) based materials have been well studied [27-30]. Exposure to the combination of UV radiation and moisture can result in more significant degradation of material as compared with samples that were exposed to UV radiation alone. Sample surfaces experience dry/wet cyclical erosion with intermittent water spray and crazing forms on the surface which enables UV penetration deeper into the polymer. Furthermore, water spray can wash away the degraded surface layer and expose a clean surface for further degradation.

Due to the limited studies that have been conducted on the weathering behavior of PHBV and therefore enhance our understanding how PHBV degrades. The aim of this work was to study the degradation mechanism of high hydroxyvalerate (HV) content PHBV during accelerated weathering. The surface morphology, chemical structure, plus thermal and mechanical properties of the PHBV film were monitored with exposure time.

\section{Experimental}

\subsection{Materials and sample preparation}

PHBV was biosynthesized in a 20 L laboratory bioreactor fed a mixture of volatile fatty acids from fermented diary manure by mixed microbial consortia inoculated with activated sludge [12, 31]. The bioreactor was aerated and operated as a sequencing batch reactor using a hydraulic and solid retention time of $4 \mathrm{~d}$. The crude $\mathrm{PHBV}$ was extracted with $\mathrm{CHCl}_{3}$ from the acetone 
prewashed lyophilized bacterial biomass at a yield of 39\%. The crude PHBV was purified by precipitation in cold petroleum ether (boiling point range $35-60{ }^{\circ} \mathrm{C}$ ) and used for subsequent experiments. The number- and weight-average molar mass $\left(\mathrm{M}_{\mathrm{n}}=7.5 \times 10^{5} \mathrm{~g} / \mathrm{mol}\right.$ and $\mathrm{M}_{\mathrm{w}}=3.7 \times$ $10^{5} \mathrm{~g} / \mathrm{mol}$, respectively) of PHBV were determined by size exclusion chromatography (SEC). The HV mol\% was $33 \%$ as determined by gas chromatography mass spectroscopy (GCMS) and ${ }^{1} \mathrm{H}-\mathrm{NMR}$ spectroscopy [12]. The isolated PHBV was dissolved in $\mathrm{CHCl}_{3}(15 \mathrm{mg} / \mathrm{mL})$, stirred for 30 min, poured into a Teflon mold to cast the PHBV films (thickness of $70 \mu \mathrm{m}$ ), air-dried, and finally vacuum dried prior to use.

\subsection{Accelerated weathering test}

Accelerated weathering tests of the PHBV films (10 replicates) were conducted in a xenon-arc weatherometer (Q-Sun Xe-1-S). The films were exposure to a repeated $2 \mathrm{~h}$ cycle of radiation followed by $2 \mathrm{~h}$ of radiation plus water spray. The average irradiance was $0.70 \mathrm{~W} / \mathrm{m}^{2}$ at $340 \mathrm{~nm}$ with a chamber temperature of approximately $70{ }^{\circ} \mathrm{C}$ (light step) [32]. The irradiance was measured and monitored regularly, and the bulb was changed periodically to maintain constant irradiance. Samples were collected periodically from 10 specimens randomly for analysis between 0 and $1000 \mathrm{~h}[27]$.

\subsection{Characterization techniques}

\subsubsection{Morphological changes}

Unweathered controls and weathered PHBV sample surfaces were observed using an Olympus BX51 optical microscope in bright field-reflection mode and images were captured using an Olympus DP70 digital camera.

\subsubsection{Size exclusion chromatography (SEC)}


The $\mathrm{M}_{\mathrm{n}}, \mathrm{M}_{\mathrm{w}}$ and polydispersity $\left(\mathrm{M}_{\mathrm{w}} / \mathrm{M}_{\mathrm{n}}\right)$ of PHBV $\left(2 \mathrm{mg} / \mathrm{mL}\right.$ in $\left.\mathrm{CHCl}_{3}\right)$ were determined by SEC. Separation was achieved using a Jordi DVB linear mixed bed column $(78 \mathrm{~mm} \times 300 \mathrm{~mm})$ at $40{ }^{\circ} \mathrm{C}$ on elution with $\mathrm{CHCl}_{3}(1 \mathrm{~mL} / \mathrm{min})$ and detected with triple detector array (refractive index, Waters model 2478), low- and right-angle laser light scattering, and differential viscometer (Viscotek model 270, Viscotek Corporation). The system was calibrated using a narrow polystyrene standard (Viscotek, $\left.\mathrm{M}_{\mathrm{w}}=98946 \mathrm{~g} / \mathrm{mol}\right)$.

The average number of chain scission per macromolecule was estimated using the method described by Sadi et al. [22]:

No. of scissions $=\mathrm{M}_{\mathrm{n}}{ }^{0} / \mathrm{M}_{\mathrm{n}}{ }^{\mathrm{t}}$

where $M_{n}{ }^{0}$ and $M_{n}{ }^{t}$ are the $M_{n}$ of unweathered and weathered PHBV after time $t(h)$, respectively.

\subsubsection{Monomeric composition by GCMS}

PHBV samples were methanolyzed at $100{ }^{\circ} \mathrm{C}$ for $4 \mathrm{~h}$ in acidified methanol $\left(3 \% \mathrm{v} / \mathrm{v}_{2} \mathrm{SO}_{4}, 2 \mathrm{~mL}\right)$ and $\mathrm{CHCl}_{3}$ containing benzoic acid as internal standard $(2 \mathrm{~mL})$. The methyl ester derivatives were analyzed by GCMS (Finnigan PolarisQ, Thermo Electron Corp.) in positive electron impact mode. Separation was achieved on a ZB1 capillary column $(30 \mathrm{~m} \times 0.25 \mathrm{~mm} \varnothing$, Phenomenex $)$ using a temperature program from $40{ }^{\circ} \mathrm{C}(2 \mathrm{~min})$ ramped to $200^{\circ} \mathrm{C}$ at $5{ }^{\circ} \mathrm{C} / \mathrm{min}$. The compounds were confirmed by their retention times and mass spectra. The HV and hydroxybutyrate (HB) mol\% was quantified relative to an internal standard and a commercial PHBV standard (22 mol\% $\mathrm{HV}$, Tianan, China) with a calibration curve $\left(\mathrm{R}^{2}>0.97\right)$.

\subsubsection{FTIR spectroscopy}

The surface chemistry of weathered PHBV samples was examined by FTIR spectroscopy using a Nicolet iS5 FTIR spectrometer (Thermo Scientific) with an attenuated total reflection (ATR) iD5 
probe $(\mathrm{ZnSe})$. The absorbance spectra of vacuum dried unweathered controls and weathered sample surfaces (in triplicate) were averaged and baseline corrected using Omnic v9.0 software (ThermoScientific).

For the quantitative analysis, the spectra were normalized and curve-fitted using Igor Prof 6.03 software (WaveMetrics). The area (A) of each band found by curve fitting was integrated by the software. In order to estimate the crystallinity changes due to weathering, the crystallization index $\left(\mathrm{I}_{\mathrm{C}=\mathrm{O}}\right)$ was calculated as the ratio of the areas $(\mathrm{A})$ under carbonyl $(\mathrm{C}=\mathrm{O})$ bands between $1800-1680 \mathrm{~cm}^{-1}[33-36]:$

$\mathrm{I}_{\mathrm{C}=\mathrm{O}}=\mathrm{A}_{1720} / \mathrm{A}_{1740}$

where $\mathrm{A}_{1720}$ and $\mathrm{A}_{1740}$ are the areas of the peaks at 1720 (crystalline portion of PHBV) and 1740 $\mathrm{cm}^{-1}$ (amorphous portion of PHBV), respectively.

The concentrations of the carbonyl $(\mathrm{C}=\mathrm{O})$ and vinyl groups $(\mathrm{C}=\mathrm{C})$ present in the WPC were determined using the Beer-Lambert equation with some assumptions [27]:

$\mathrm{A}=\varepsilon b c$

where A is the absorbance of the band obtained from FTIR spectra, $\mathrm{c}$ is the molar concentration in $\mathrm{mol} / \mathrm{L}(\mathrm{M})$ relative to the functional group, $\varepsilon$ is the molar absorptivity $(\mathrm{L} / \mathrm{mol} / \mathrm{cm})$, and $\mathrm{b}$ is the path length of the sample (i.e., optical path of the beam through the sample, $\mathrm{cm}$ ). Molar absorptivity $\varepsilon$ values used in this study were taken from the literature [37] using model compounds where esters $\left(\mathrm{C}=\mathrm{O}, 1720 \mathrm{~cm}^{-1}\right)$ and vinyl $\left(\mathrm{C}=\mathrm{C}, 910 \mathrm{~cm}^{-1}\right)$ were 590 and 121 $\mathrm{L} / \mathrm{mol} / \mathrm{cm}$, respectively. 
Optical path length $b$ was considered to be the effective path-length (I). Effective path-length can be calculated from the following equation:

$\mathrm{I}=\mathrm{d}_{\mathrm{p}} \times \mathrm{N}$

where $d_{p}$ is the depth of penetration of the radiation and $\mathrm{N}$ represents the number of total internal reflections that occurred in the ATR crystal. However, for the ATR crystal used in this study, N $=1$ (single bounce). Therefore, equation (4) can be rewritten into

$\mathrm{I}=\mathrm{d}_{\mathrm{p}}$

According to Averett [38], I is twice the $d_{p}$ for a polarized ZnSe ATR crystal. Thus,

$\mathrm{I}=2 \mathrm{~d}_{\mathrm{p}}$

and $d_{p}$ can be stated as:

$\mathrm{d}_{\mathrm{p}}=\frac{\lambda}{2 \pi \cdot \mathrm{n}_{1}\left(\sin ^{2} \theta_{\mathrm{ef}}-\mathrm{n}_{21}^{2}\right)^{\frac{1}{2}}}$

where $d_{p}$ is the depth of penetration in $\mathrm{cm}, \lambda$ is the wavelength in $\mathrm{cm}\left(\lambda_{1720}=5.8140 \times 10^{-4} \mathrm{~cm}\right.$; $\left.\lambda_{910}=1.0989 \times 10^{-3} \mathrm{~cm}\right), \mathrm{n}_{1}$ represents the refractive index of the ATR crystal $\mathrm{n}_{1}\left(\right.$ at $\left.1000 \mathrm{~cm}^{-1}\right)=$ 2.43 for $\mathrm{ZnSe}$, and the refractive index $\left(\mathrm{n}_{2}\right)$ of PHBV was assumed to be equal to 1.5 [39].

Refractive index $n_{21}$ is the ratio between the refraction index of the sample $\left(n_{2}\right)$ and the refraction index of the ATR crystal $\left(n_{1}\right)$ that $n_{21}=0.6173$. $\theta_{\text {ef }}$ is the effective angle of incidence in degrees $\left(45^{\circ}\right)$. Therefore, the concentration can be obtained from the following equation:

$\mathrm{C}=\frac{\mathrm{A}}{2 \mathrm{~d}_{\mathrm{p}} \cdot \varepsilon}$

\subsubsection{NMR spectroscopy}


Samples were dissolved in $\mathrm{CDCl}_{3}(5 \mathrm{mg} / \mathrm{mL})$ and ${ }^{1} \mathrm{H}-\mathrm{NMR}$ spectra were recorded on an Advance Bruker $300 \mathrm{MHz}$ spectrometer at $27^{\circ} \mathrm{C}$. Spectra were analyzed using SpinWorks v3.1.7 software.

\subsubsection{Differential scanning calorimetry (DSC)}

DSC was performed on PHBV samples (4-6 mg, in duplicate) using a TA Instruments model Q200 DSC with refrigerated cooling. The samples were (i) equilibrated at $40{ }^{\circ} \mathrm{C}(3 \mathrm{~min})$ then ramped to $180{ }^{\circ} \mathrm{C}$ at $10{ }^{\circ} \mathrm{C} / \mathrm{min}$ to destroy any thermal history and held isothermally for $3 \mathrm{~min}$, (ii) cooled to $-50{ }^{\circ} \mathrm{C}$ at $10{ }^{\circ} \mathrm{C} / \mathrm{min}$ and held isothermally for $3 \mathrm{~min}$ and then cycles were repeated. The melting $\left(T_{m}\right)$ and glass $\left(T_{g}\right)$ transition temperatures were determined from the peak maximum and the inflection point of the second heating scan, respectively. The degree of crystallization $\left(\mathrm{X}_{\mathrm{t}} \%\right)$ of samples were calculated from the ratio of the melting enthalpy $\left(\Delta \mathrm{H}_{\mathrm{m}}\right)$ of the sample to $\left(\Delta \mathrm{H}_{\mathrm{m}}{ }^{0}\right)$ of $100 \%$ crystalline polymers (146 J/g/ ${ }^{\circ} \mathrm{C}$ for PHB) [40]. Data were analyzed using TA Universal Analysis v5.4A software.

\subsubsection{Tensile testing}

Unweathered and weathered PHBV samples were randomly selected and cut into $10 \times 3 \times 0.075$ $\mathrm{mm}^{3}$ sized specimens (7 replicates). Tensile testing was performed on a DMA Q800 (TA instruments) with controlled force of $2 \mathrm{~N} / \mathrm{min}$ was applied until specimen failure. Tensile strength $(\sigma)$, Young's modulus $(E)$, and elongation to break $(\varepsilon \%)$ were determined from the constructed stress-strain curve using Universal Analysis v5.4A software [41].

\section{Results and discussion}

\subsection{Degradation mechanisms of PHBV during weathering}


Fig. 1 shows the four major types of photodegradation mechanisms in polymers. Traditionally, during polymer (i.e. HDPE) degradation chain scissioning occurs via Norrish Type I and II reactions (Fig. 1a and b) [29]. Radical intermediates are formed during Norrish Type I reactions in the presence of UV radiation. These free radicals tend to attack the less stable tertiary $\mathrm{H}$ of $\mathrm{HB}$ and HV units and initiate the chain cleavage, followed by further photo-oxidation of PHBV (Fig. 1c). Degradation via $\beta$-scission will generate new species, and therefore a higher concentration of carbonyl $(\mathrm{C}=\mathrm{O})$ groups would be observed. Lower molar mass polymers will be produced by scission with changes in sample morphology and thermophysical properties. Meantime, radicals, $\mathrm{C} \cdot$ and $-\mathrm{C}-\mathrm{O}-\mathrm{O}$, produced by radical initiation can undergo crosslinking reactions to form $\mathrm{C}-\mathrm{C}$ or -C-O-O-C- linkages between HB-HB, HB-HV, and HV-HV units from different molecular chains (Fig. 1d). The C-O-O-C- linkage is not stable and will undergo a $\beta$-scission reaction. Due to limited mobility of solid samples during weathering, the crosslinking reaction could at least be possible as compared to the other three types of mechanisms. It is noted that, except the photodegradation mechanisms described above, some extent of hydrolysis of ester bands of PHBV could occur during weathering due to the presence of water. As postulated if acids are generated through a Norrish Type II mechanism the acidic environment can result in the hydrolysis of PHBV, and therefore a decrease of carbonyl groups would be expected. 


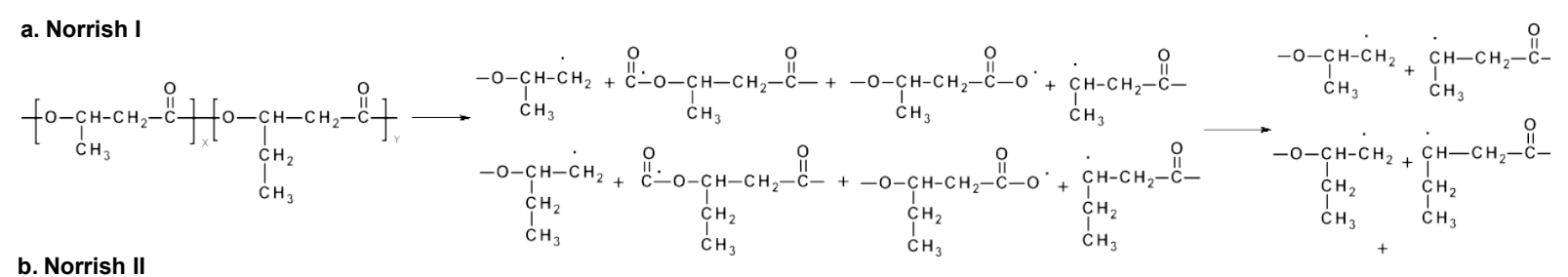

b. Norrish II

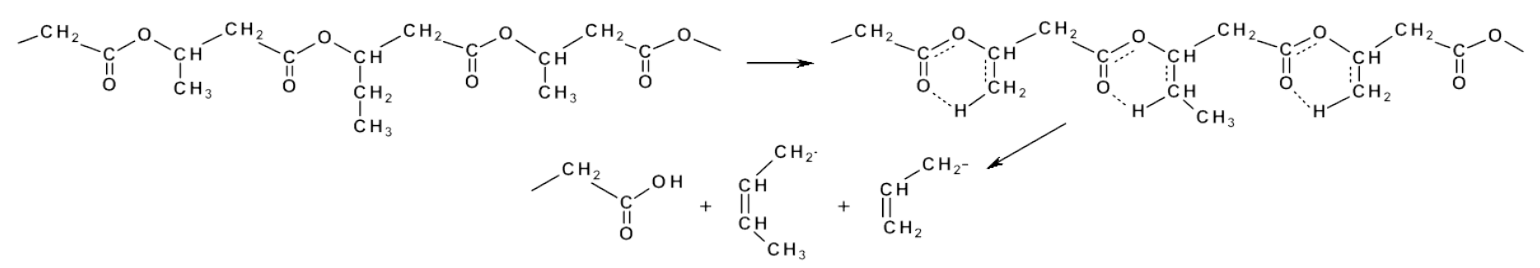

c. Radical initiation

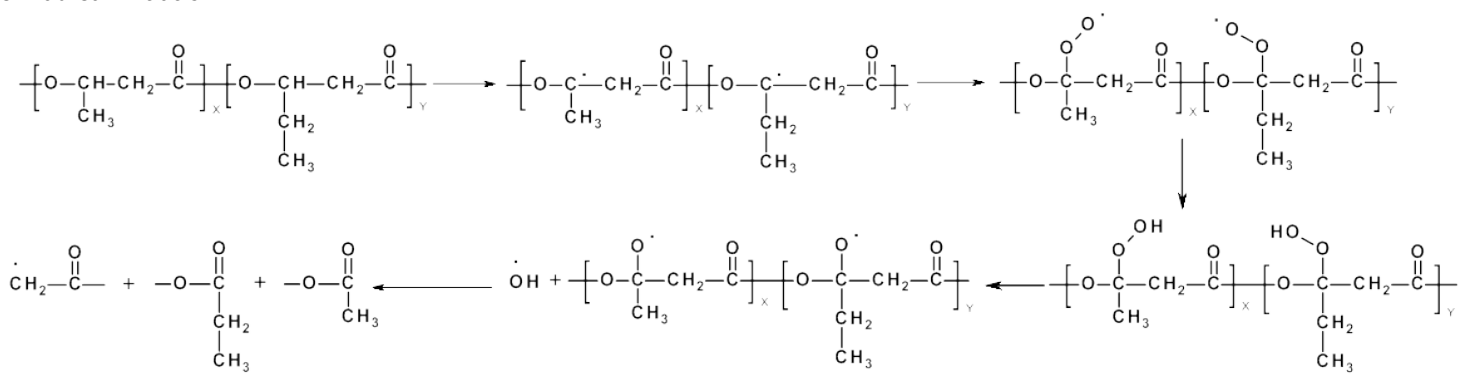

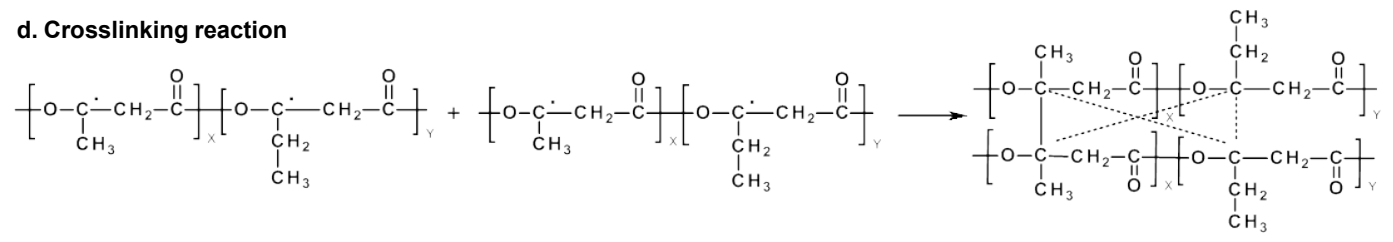

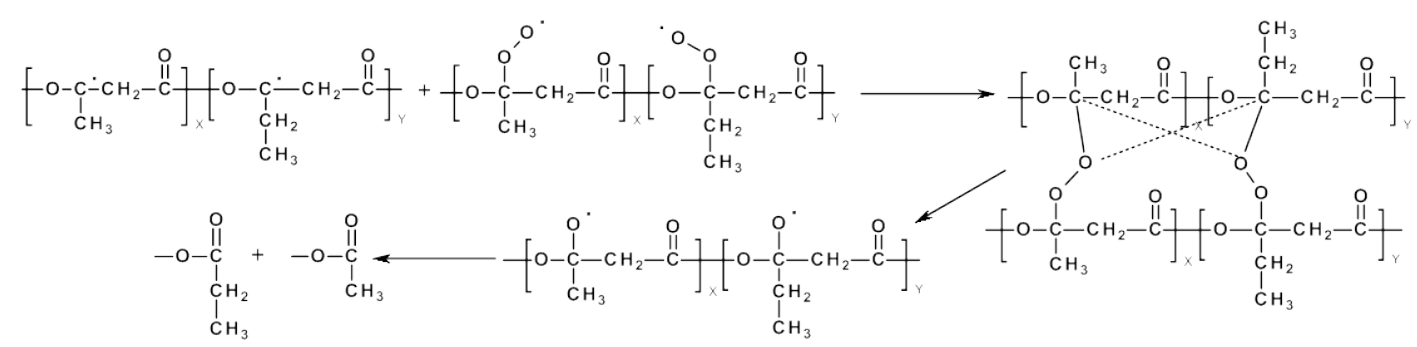

Fig. 1. Photodegradation reaction mechanisms of PHBV: (a) Norrish I, (b) Norrish II, (c) radical initiation, and (d) crosslinking.

\subsection{Visual appearance changes}

Inspection of the PHBV surfaces after $500 \mathrm{~h}$ accelerated weathering by microscopy showed visible cracks (also known as crazing) (Fig. 2b). After weathering the PHBV film surfaces 
became rough. The size of these cracks or checks was shown to increase with extended weathering to1000 h (Fig. 2c). Similarly to other weathered polymers, e. g. HDPE and PP, the crazing of weathered PHBV surfaces was likely caused by polymer chain scission/cleavage leading to the creation of highly crystallized PHBV regions [28]. These regions tend to contract and expand during the drying (with light) and wetting (light and water spray) cycles, respectively. Initial checking formed on the surfaces would facilitate UV penetration into the bulk of the polymer. Water spray will also wash away any debris from the degraded surface and promote crazing [28], which would disorient the crystal lamella in the deeper layers. This observation agrees with the morphological investigation of photodegraded bioplastics such as PLA, PCL, and PHB $[9,22,26]$. These results show that PHBV was susceptible to degradation by accelerated weathering.
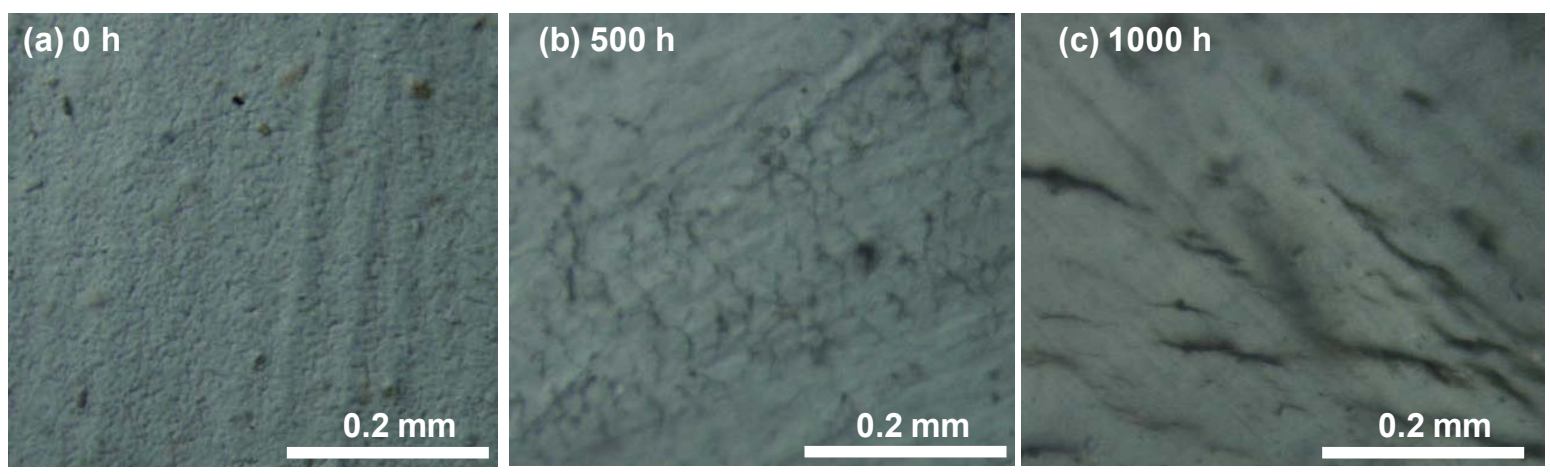

Fig. 2. Light micrographs $(200 \times)$ of PHBV control (a) and after accelerated weathering for 500 h (b) and $1000 \mathrm{~h}(\mathrm{c})$.

\subsection{Chemical changes of PHBV copolymer during weathering}

\subsubsection{Molecular weight changes}


Molar mass changes and number of chain scissions as a result of weathering PHBV were determined and given in Table 1. As exposure time was increased to $800 \mathrm{~h}$, the $\mathrm{M}_{\mathrm{n}}$ decreased, while the number of scissions of molecular chains was increased gradually. However, 800 to $1000 \mathrm{~h}$ exposure, the changes were not so apparent, reflecting that the molecular degradation occurred at the PHBV film surface. This confirms the postulation proposed earlier, that chainscissioning occurred via Norrish I/II and radical initiation mechanisms (Fig. $1 \mathrm{a}, \mathrm{b}$ and c). The degradation rate $(k)$ was estimated from the slope of the $\ln \left(\mathrm{M}_{n}{ }^{0} / \mathrm{M}_{n}{ }^{\mathrm{t}}\right)$ vs. weathering time $(\mathrm{t}=0$ $1000 \mathrm{~h}$ ) data. The $\mathrm{k}$ values were $1.2 \times 10^{-3} \mathrm{~h}^{-1}$ and $2.2 \times 10^{-3} \mathrm{~h}^{-1}$ for the weathering time that was from 0 to $1000 \mathrm{~h}$ and $200 \mathrm{~h}$, respectively, which are in the range of for amorphous $\left(1.56 \times 10^{-3} / \mathrm{h}\right)$ and crystalline $\left(3.69 \times 10^{-3} / \mathrm{h}\right)$ PLA reported by Tsuji et al [9]. This result indicates that PHBV degradation was more severe at the early stage $(<200 \mathrm{~h})$ of weathering and was more gradual with extended exposure.

Table 1. Chemical changes of PHBV before and after weathering.

\begin{tabular}{llllllll}
\hline $\begin{array}{l}\text { Exposure } \\
\text { time (h) }\end{array}$ & $\begin{array}{l}\mathrm{M}_{\mathrm{n}}\left(\times 10^{5}\right. \\
\mathrm{g} / \mathrm{mol})\end{array}$ & $\mathrm{M}_{\mathrm{w}} / \mathrm{M}_{\mathrm{n}}$ & $\mathrm{M}_{\mathrm{n}}{ }^{0} \mathrm{M}_{\mathrm{n}}{ }^{\mathrm{t}}$ & $\mathrm{k}\left(\mathrm{h}^{-1}\right)$ & $\mathrm{HV}(\mathrm{mol} \%)$ & $\begin{array}{l}\mathrm{C}_{1720} \\
(\mathrm{~mol} / \mathrm{kg})\end{array}$ & $\begin{array}{l}\mathrm{C}_{910} \\
(\mathrm{~mol} / \mathrm{kg})\end{array}$ \\
\hline 0 & 3.51 & 2.03 & 1.00 & & $33.1 \pm 1.2$ & 3.58 & 1.10 \\
120 & 2.59 & 2.37 & 1.36 & & $29.5 \pm 0.5$ & 2.38 & 1.40 \\
200 & 2.32 & 2.40 & 1.51 & $2.2 \times 10^{-3}$ & $30.8 \pm 0.2$ & 2.37 & 1.53 \\
400 & 2.05 & 2.82 & 1.71 & & $28.3 \pm 1.3$ & 3.11 & 1.56 \\
600 & 1.84 & 3.06 & 1.91 & & $30.0 \pm 0.8$ & 3.48 & 1.63 \\
800 & 1.32 & 3.55 & 2.66 & & $33.3 \pm 0.3$ & 3.53 & 1.68 \\
1000 & 1.30 & 3.56 & 2.70 & $1.2 \times 10^{-3}$ & $38.6 \pm 1.1$ & 3.53 & 1.70 \\
\hline
\end{tabular}

\subsubsection{Compositional changes}


The copolymer composition (molar fraction of HV monomer) was determined as their methyl ester derivatives by GCMS and the results are given in Table 1. In the first $600 \mathrm{~h}, \mathrm{HV}$ mol\% was reduced by $10 \%$, suggesting the preference of degradation of $\mathrm{HV}$ units over $\mathrm{HB}$ units. However, at the end of weathering the HV molar content was increased from 33 to $39 \mathrm{~mol} \%$.

Compositional analysis indicated that the degradation of PHBV was non-random. The HV units degraded mainly at the early weathering stage to a certain level then chain cleavage at HB units was favored. It was reported that the hydrolysis of PHBV (6 mol\% HV) favors the HV units with longer exposure time [13]. Therefore, the accelerated weathering degradation of PHBV copolymer is dependent on HV content.

\subsubsection{Surface chemistry -}

FTIR spectroscopic analyses were used to investigate the chemical surface changes during weathering. The FTIR spectra of unweathered control and weathered (500 and $1000 \mathrm{~h}$ ) PHBV are shown in Fig. 3. The intensity of the ester carbonyl $\left(\mathrm{C}=\mathrm{O}, 1800-1680 \mathrm{~cm}^{-1}\right)$ and $\mathrm{C}-\mathrm{O}$ stretching (1070-1020 $\left.\mathrm{cm}^{-1}\right)$ bands were increased upon weathering especially after $500 \mathrm{~h}$, showing strong evidence of photo-oxidation of PHBV. The specific carbonyl $\left(1800-1680 \mathrm{~cm}^{-1}\right)$ and vinyl $\left(\mathrm{C}=\mathrm{C}\right.$ at $\left.910 \mathrm{~cm}^{-1}\right)$ groups were examined in detail to determine the extent of PHBV oxidation. The concentrations of these groups were calculated using Equations (3-8) and results are given in Table 1. The PHBV ester $\mathrm{C}=\mathrm{O}$ concentration $\left(\mathrm{C}_{1720}\right)$ was shown to decrease in the initial weathering stage $(<200 \mathrm{~h})$ but increased on extended weathering $(>200 \mathrm{~h})$. As stated above hydrolysis of PHBV could result in the reduction of ester $\mathrm{C}=\mathrm{O}$ groups; hence, in the initial weathering stage the hydrolysis of ester bond of PHBV was dominant, whereas with extended weathering time $\beta$-scission prevailed over hydrolysis. However, the vinyl concentration $\left(\mathrm{C}_{910}\right)$ was shown to increase with exposure time. These findings provide evidence that PHBV 
experienced Norrish Type II reactions, resulting in the formation of vinyl groups and unsaturated $\mathrm{C}=\mathrm{C}$ bonds $[9,29]$, especially at an early stage. In addition, Norrish Type I reaction generate free radicals $\left(\mathrm{R}^{\cdot}\right)$ intermediates in the presence of UV radiation which further initiates the polymer chain cleavage and forms carbonyl groups [22].

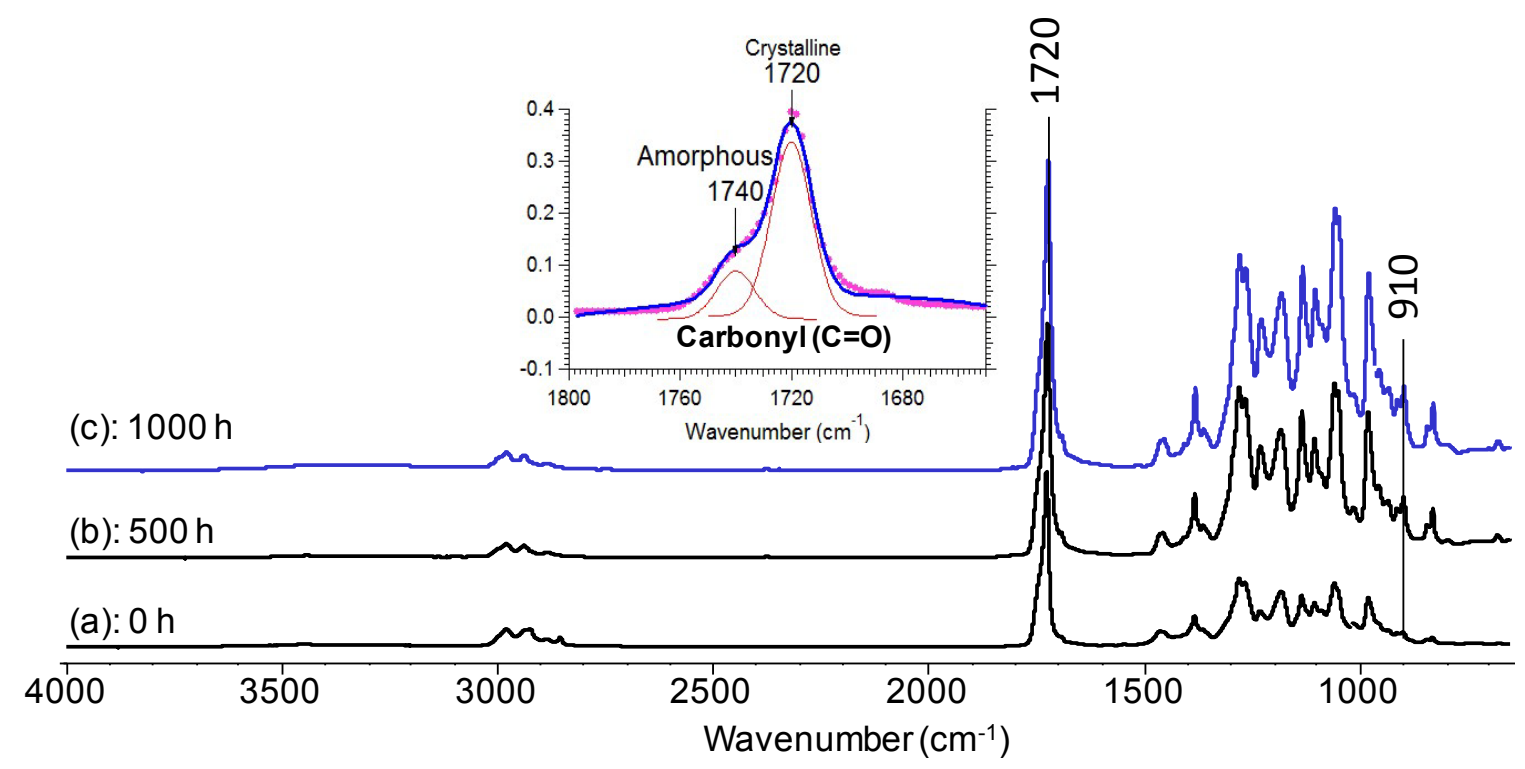

Fig. 3. FTIR spectra of PHBV films unweathered control (a) and weathered for (b) $500 \mathrm{~h}$ and (c) $1000 \mathrm{~h}$.

\subsubsection{Structural changes}

${ }^{1} \mathrm{H}$ NMR spectroscopy was employed to monitor functional group changes in the bulk PHBV during weathering. Fig. 4 shows ${ }^{1}$ H-NMR spectra of unweathered control and $1000 \mathrm{~h}$ weathered PHBV samples. The triplet $\mathrm{CH}_{3}$ proton resonance at $\delta=0.95 \mathrm{ppm}$ corresponds to the methyl groups of $\mathrm{HV}$ monomer unit, while the doublet $\mathrm{CH}_{3}$-proton resonance at $\delta=1.31 \mathrm{ppm}$ was assigned to methyl group of HB monomer. The chemical shift observed at $\delta=1.68 \mathrm{ppm}$ was attributed to the $\mathrm{CH}_{2}$-proton resonance of $\mathrm{HV}$ units $[12,42]$. The $\mathrm{CH}$-proton of $\mathrm{HB} / \mathrm{HV}$ units shows resonance at $\delta=5.12-5.30 \mathrm{ppm}$. These signals did not show an apparent change upon 
weathering. After $1000 \mathrm{~h}$ weathering, the spectrum showed the presence of one new signal at $\delta=$ 2.04 ppm (Fig. 4b), which could be assigned to the $\mathrm{CH}_{3}$-proton of $\mathrm{HB}$ [22], or $\mathrm{CH}_{2}$-proton of $\mathrm{HV}$ being directly connected to a carbonyl group $(\mathrm{C}=\mathrm{O})$ as proposed in Fig. 1. This finding is in agreement with results reported in the literature for photodegraded PHB [22]. Therefore, it is highly possible that the degradation mechanism of PHBV follows the mechanisms of radical initiation (Fig. 1c) which was produced via the Norrish type I reaction (Fig. 1a).

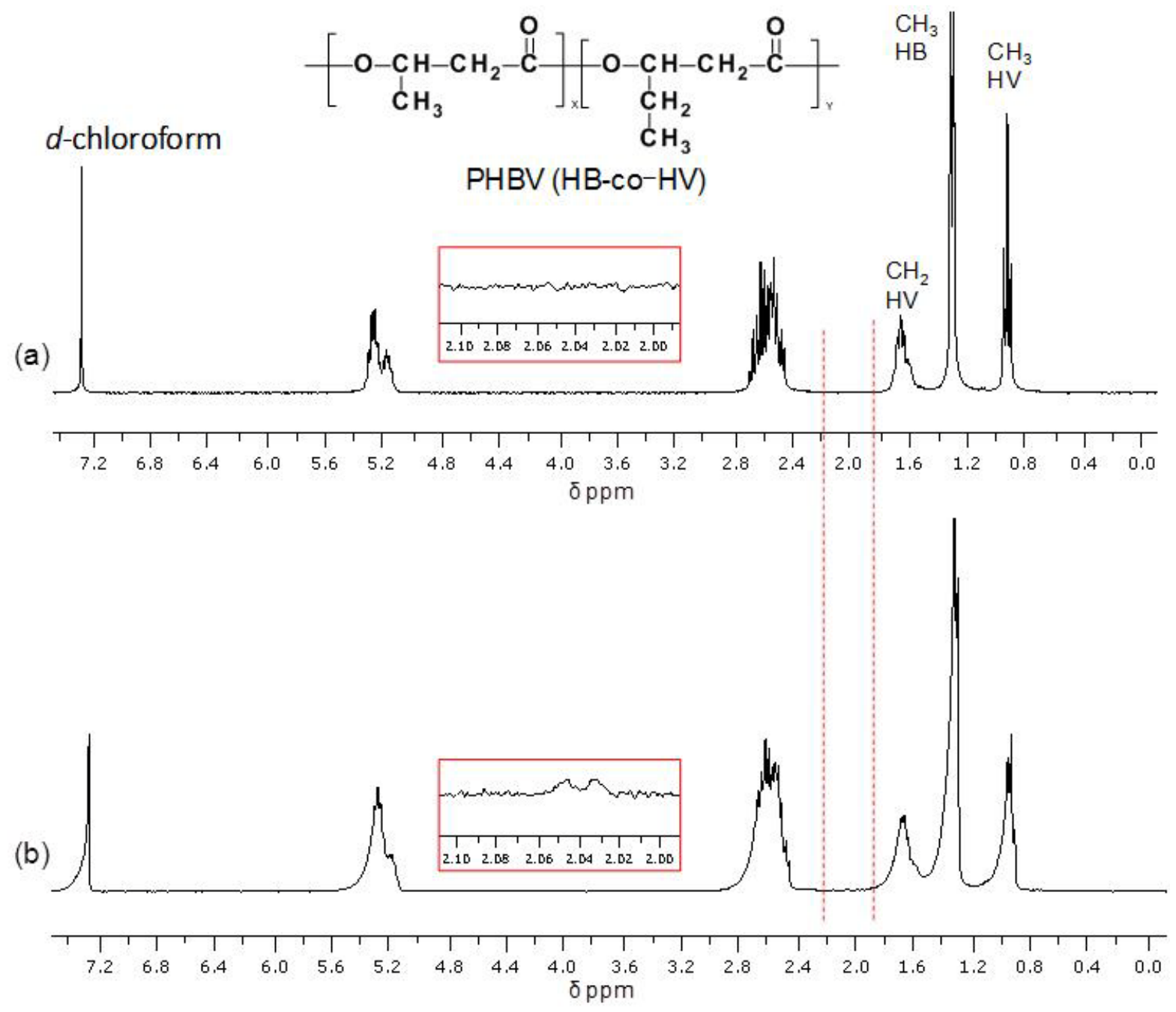

Fig. 4. ${ }^{1} \mathrm{H}-\mathrm{NMR}$ spectra of PHBV that was (a) unweathered control and (b) weathered for $1000 \mathrm{~h}$. 


\subsection{Thermal properties changes}

The surface morphology of weathered PHBV films showed that they were more crystalline as compared to unweathered controls. Detailed information of the PHBV crystallization behavior changes was obtained from DSC and FTIR analyses. As shown in Fig. 5, the degree of crystallinity $\left(\mathrm{X}_{\mathrm{t}} \%\right)$ in PHBV by DSC increased 6-fold after the initial weathering stage $(<200 \mathrm{~h})$. Between 200 to $600 \mathrm{~h}$ of exposure the PHBV $\mathrm{X}_{\mathrm{t}} \%$ was relatively constant at about $13 \%$. On extended exposure (> $600 \mathrm{~h}$ ) the PHBV $\mathrm{X}_{\mathrm{t}} \%$ was increased significantly to about $19 \%$. An increase in degree of crystallinity was also observed in photodegraded PCL films exposed to radiation for $200 \mathrm{~h}$ [9].

The spectral ratio of band $1720 / 1740 \mathrm{~cm}^{-1}$ (crystallinity index, $\mathrm{I}_{\mathrm{C}=0}$ ) can be used to estimate the degree of crystallinity of PHB [33, 34, 43]. The FTIR ester carbonyl band $\left(1800-1680 \mathrm{~cm}^{-1}\right)$ was curve fitted (the inset spectrum of Fig. 3). There was a similar trend between $\mathrm{I}_{\mathrm{C}=\mathrm{O}}$ and $\mathrm{X}_{\mathrm{t}} \%$ changes for the weathered PHBV (Fig. 5). Due to Norrish Type I/II and radical initiation reactions, the reduction in the density of PHBV polymer chain entanglements would allow lowmolar mass fragments to more readily align/crystallize from the melt (during DSC analysis) due to their higher mobility. Moreover, the thickening of crystals during weathering of PHBV can result in an increase of degree of crystallinity of upon weathering. It is worth noting that with the presence of water spray this can contribute to deeper UV penetration through checks formed at an early stage of exposure. Based on the influence of water spray, the $\mathrm{X}_{\mathrm{t}} \%$ of PHBV was increased to around $19 \%\left(\Delta \mathrm{H}_{\mathrm{m}}=27.7 \mathrm{~J} / \mathrm{g}\right)$ after $1000 \mathrm{~h}$ of accelerated weathering as compared to a crystallinity of $14 \%\left(\Delta \mathrm{H}_{\mathrm{m}}=20.4 \mathrm{~J} / \mathrm{g}\right)$ for PHB exposed to UV irradiation for 12 weeks [22]. 


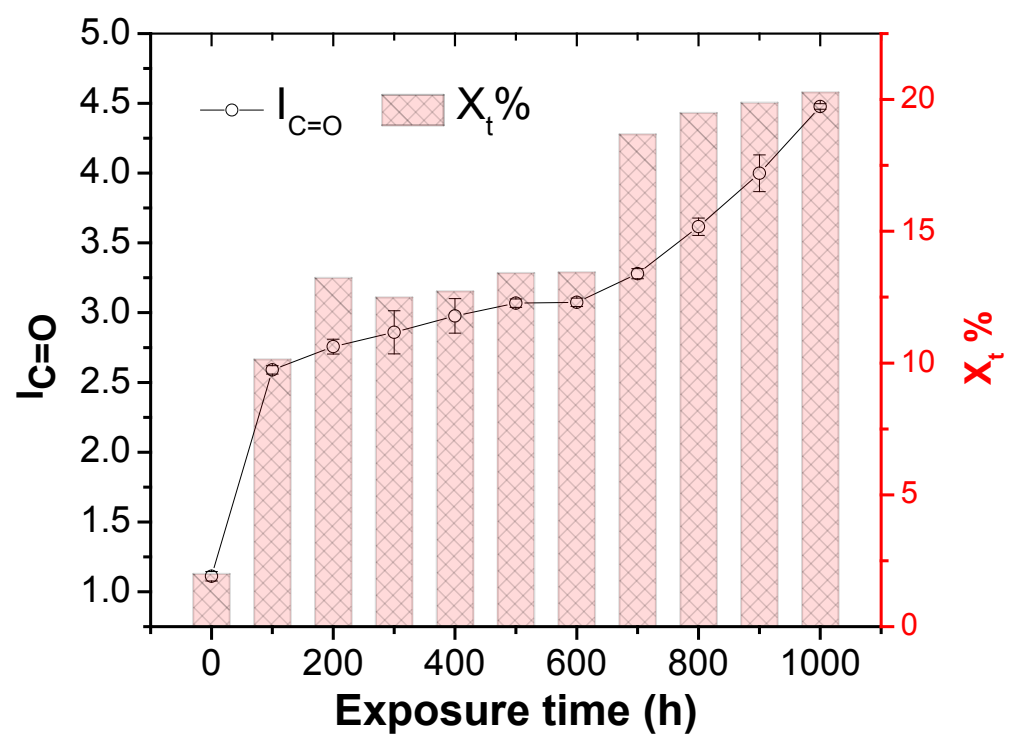

Fig. 5. Crystallinity changes of PHBV with weathering (0-1000 h).

The melting $\left(\mathrm{T}_{\mathrm{m}}\right.$ around $\left.163{ }^{\circ} \mathrm{C}\right)$ and glass transition temperatures $\left(\mathrm{T}_{\mathrm{g}}\right.$ around $\left.-2.5^{\circ} \mathrm{C}\right)$ of weathered PHBV films were relatively constant with exposure time (Fig. 6). This may be because the lamellar structure of PHBV was not influenced during the accelerated weathering. For gamma and electric irradiation treated PHB/PHBV a significant decrease in $\mathrm{T}_{\mathrm{m}}$ was observed $[44,45]$. This phenomenon suggests a wider molar mass distribution (Table 1 , higher $M_{w} / M_{n}$ ) and lower chain stiffness due to chain-scissioning (e.g., $\beta$-scission as shown in Fig. 1c) upon weathering [46]. Although, some crosslinking could occur due to photodegradation (Fig. 1d) the main degradation mechanism is chain cleavage than crosslinking. 
Fig. 6. $P H B V T_{m}$ and $T_{g}$ changes with exposure time $(0-1000 h)$.

\subsection{Effect of weathering on tensile property of PHBV}

The PHBV tensile properties were monitored with exposure time (Fig. 7). Before weathering the PHBV film had $E, \sigma$, and $\varepsilon \%$ values of $322 \mathrm{MPa}, 15.7 \mathrm{MPa}$, and $53.5 \%$, respectively. At just 24 h exposure, the $E$ was increased by $30 \%$, while the $\varepsilon \%$ was reduced by $46 \%$. The PHBV $\sigma$ and $\varepsilon \%$ were shown to decrease with weathering time and most likely due to a decrease in molar mass. However, the $E$ was shown to increase as the PHBV degree of crystallinity increased. It is worth noting that $\sigma$ was decreased significantly when the exposure time was $>700 \mathrm{~h}$. The tensile specimens experienced stretching and necking behavior when PHBV exposure time was $<700 \mathrm{~h}$ (Fig. 7 inset image). In contrast, above $700 \mathrm{~h}$ exposure the PHBV tensile specimens were shown to completely break apart (Fig. 7). The changes of $E, \sigma$, and $\varepsilon \%$ indirectly suggest that crosslinking reactions occurred in addition to chain scissioning during weathering. Limited 
amount of crosslinking can recover some degree of mechanical property while chain scissioning is more detrimental $[22,44]$.

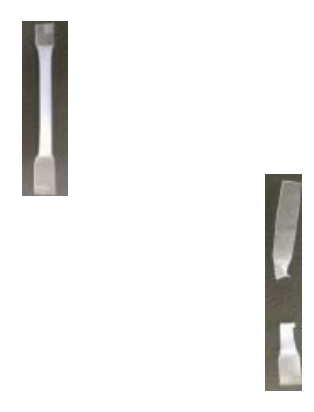

Fig. 7. Tensile property $(E, \varepsilon$, and $\sigma)$ changes of PHBV with exposure time $(0-1000 \mathrm{~h})$.

\section{Conclusions}

In this study, the effect of weathering on the chemical, thermal and mechanical properties on PHBV copolymer was investigated. Weathering of PHBV followed five types of degradation mechanisms: (1) Norrish Type I, (2) Norrish Type II, (3) radical initiation, (4) crosslinking reaction, and some extent of (5) hydrolysis of ester bonds. Weathering of PHBV was more severe with the presence of water spray. Compositional analysis (HV mol\%) showed the HV units degraded mainly at the early weathering stage, while the chain cleavage at HB unit was to be favored with weathering was extended. ${ }^{1} \mathrm{H}-\mathrm{NMR}$ results and carbonyl group concentration determined by FTIR indicated a great amount of $\beta$-scission occurred during weathering. Weathered PHBV exhibited an increase in degree of crystallinity to $20 \%$. The ultimate strength 
and elongation to break were decreased, while the Young's modulus $(E)$ was increased with weathering. Hence, the PHBV is not just biodegradable but also photodegradable to solar radiation in the presence of water.

\section{Acknowledgement}

The authors would like to acknowledge (i) the financial support from a USDA Forest Products Laboratory grant 08-JV-111111, (ii) Dr. Erik R. Coats and Nicolas Guho (Department of Civil Engineering, University of Idaho) for kindly providing PHA biomass, and (iii) ThermoScientific for the iS5 FTIR spectrometer.

\section{References}

[1] Li J, Hunt JF, Gong S, Cai Z. High Strength Wood-based Sandwich Panels Reinforced with Fiberglass and Foam. BioResources. 2014;9:1898-1913.

[2] Li J, Hunt JF, Cai Z, Zhou X. Bending analyses for 3D engineered structural panels made from laminated paper and carbon fabric. Compos Part B: Eng 2013;53:17-24.

[3] Luengo JM, García B, Sandoval A, Naharro G, Olivera EaR. Bioplastics from microorganisms. Curr Opin Microbiol 2003;6:251-260.

[4] Ma X, Zhang F, Wei L. Effect of wood charcoal contents on the adsorption property, structure, and morphology of mesoporous activated carbon fibers derived from wood liquefaction process. J Mater Sci. 2014;50:1908-1914.

[5] Li J, Hunt JF, Gong S, Cai Z. Testing and Evaluation of a Slot and Tab Construction Technique for Light-Weight Wood-Fiber-Based Structural Panels Under Bending. J Test Eval 2016;44:1-10.

[6] Bugnicourt E, Cinelli P, Lazzeri A, Alvarez V. Polyhydroxyalkanoate (PHA): Review of synthesis, characteristics, processing and potential applications in packaging. Express Polym Lett. 2014;8:791-808.

[7] Song K, Wu Q, Zhang Z, Ren S, Lei T, Dooley KM, et al. Fabricating electrospun nanofibers with antimicrobial capability: A facile route to recycle biomass tar. Fuel. 2015;150:123-130. 
[8] Sun L, Wu Q, Xie Y, Song K, Lee S, Wang Q. Thermal decomposition of fire-retarded wood flour/polypropylene composites. J Therm Anal Calorim. 2015; Doi: 10.1007/s10973-015-4971-8.

[9] Tsuji H, Echizen Y, Nishimura Y. Photodegradation of biodegradable polyesters: A comprehensive study on poly(l-lactide) and poly( $\varepsilon$-caprolactone). Polym Degrad Stab. 2006;91:1128-1137.

[10] Li J, Hunt JF, Gong S, Cai Z. Simplified Analytical Model and Balanced Design Approach for Light-Weight Wood-Based Structural Panel in Bending. Compos Struct. 2015;Doi:10.1016/j.compstruct.2015.09.045.

[11] Li J, Hunt JF, Gong S, Cai Z. Wood-based Tri-Axial Sandwich Composite Materials: Design, Fabrication, Testing, Modeling and Application. Proceedings Composites and Advanced Materials Expo. 2014:1-16.

[12] Wei L, Guho NM, Coats ER, McDonald AG. Characterization of poly(3-hydroxybutyrateco-3-hydroxyvalerate) biosynthesized by mixed microbial consortia fed fermented dairy manure. J Appl Polym Sci. 2014;131:40333, Doi: 10.1002/app.40333.

[13] dos Santos Rosa D, Calil MR, Guedes CdGF, Rodrigues TC. Biodegradability of Thermally Aged PHB, PHB-V, and PCL in Soil Compostage. J Polym Environ. 2004;12:239-245.

[14] Iwata T, Doi Y, Tanaka T, Akehata T, Shiromo M, Teramachi S. Enzymatic Degradation and Adsorption on Poly[(R)-3-hydroxybutyrate] Single Crystals with Two Types of Extracellular PHB Depolymerases from Comamonas acidovorans YM1609 and Alcaligenes faecalis T1. Macromolecules. 1997;30:5290-5296.

[15] Lee SY, Choi J-i. Production and degradation of polyhydroxyalkanoates in waste environment. Waste Manage 1999;19:133-139.

[16] Sudesh K, Abe H, Doi Y. Synthesis, structure and properties of polyhydroxyalkanoates: biological polyesters. Prog Polym Sci. 2000;25:1503-1555.

[17] Tsuji H, Suzuyoshi K. Environmental degradation of biodegradable polyesters 1. Poly(ecaprolactone), poly[(R)-3-hydroxybutyrate], and poly(L-lactide) films in controlled static seawater. Polym Degrad Stab. 2002;75:347-355.

[18] Kim M-N, Lee A-R, Yoon J-S, Chin I-J. Biodegradation of poly(3-hydroxybutyrate), SkyGreen ${ }^{\circledR}$ and Mater-Bi ${ }^{\circledR}$ by fungi isolated from soils. Eur Polym J. 2000;36:1677-1685.

[19] Wei L, Liang S, McDonald AG. Thermophysical properties and biodegradation behavior of green composites made from polyhydroxybutyrate and potato peel waste fermentation residue. Ind Crop Prod. 2015;69:91-103.

[20] Eldsater C, Karlsson S, Albertsson A-C. Effect of abiotic factors on the degradation of poly(3-hydroxybutyrate-co-3-hydroxyvalerate) in simulated and natural composting environments. Polym Degrad Stab. 1999;64:177-183. 
[21] Iwata T, Doi Y, Kasuya K-i, Inoue Y. Visualization of enzymatic degradation of poly[(R)-3hydroxybutyrate] single crystals by an extracellular PHB depolymerase. Macromolecules 1997;30:833-839.

[22] Sadi RK, Fechine GJM, Demarquette NR. Photodegradation of poly(3-hydroxybutyrate). Polym Degrad Stab. 2010;95:2318-2327.

[23] Ivanov VB, Khavina EY, Voinov SI, Ol'Khov AA. Photooxidation of polyhydroxybutyrate. Int Polym Sci Technol 2009;36:19-22.

[24] dos Santos Rosa D, Calil MR, Guedes CdGaF, Santos CEO. The effect of UV-B irradiation on the biodegradability of poly- $\beta$-hydroxybutyrate (PHB) and poly- $\varepsilon$-caprolactone (PCL). J Polym Environ. 2001;9:109-113.

[25] Ikada E. Relationship between photodegradability and biodegradability of some aliphatic polyesters. J Photopolym Sci Technol. 1999;12:251-256.

[26] Tsuji H, Sugiyama H, Sato Y. Photodegradation of Poly(lactic acid) Stereocomplex by UVIrradiation. J Polym Environ 2012;20:706-712.

[27] Wei L, McDonald AG, Freitag C, Morrell JJ. Effects of wood fiber esterification on properties, weatherability and biodurability of wood plastic composites. Polym Degrad Stab. 2013;98:1348-1361.

[28] Stark NM, Matuana LM. Influence of photostabilizers on wood flour-HDPE composites exposed to xenon-arc radiation with and without water spray. Polym Degrad Stab. 2006:30483056.

[29] Fabiyi JS, McDonald AG, Wolcott MP, Griffiths PR. Wood plastic composites weathering: Visual appearance and chemical changes. Polym Degrad Stab. 2008;93:1405-1414.

[30] Li H, Zhang Z, Song K, Lee S, Chun S-J, Zhou D, et al. Effect of Durability Treatment on Ultraviolet Resistance, Strength, and Surface Wettability of Wood Plastic Composite.

BioResources. 2014;9:3591-3601.

[31] Wei L, Liang S, Guho NM, Hanson AJ, Smith MW, Garcia-Perez M, et al. Production and characterization of bio-oil and biochar from the pyrolysis of residual bacterial biomass from a polyhydroxyalkanoate production process. J Anal Appl Pyrolysis. 2015;115:268-278.

[32] American Society for Testing and Materials (ASTM D6662-13). Standard test method for flexural properties of unreinforced and reinforced plastics and electrical insulating materials. In Annual book of ASTM standards 2013; vol. (08)03. West Conshohocken, PA

[33] Wei L, McDonald AG, Stark NM. Grafting of bacterial polyhydroxybutyrate (PHB) onto cellulose via in-situ reactive extrusion with dicumyl peroxide. Biomacromolecules. 2015;16:1040-1049. 
[34] Wei L, Stark NM, McDonald AG. Interfacial improvements in biocomposites based on poly(3-hydroxybutyrate) and poly(3-hydroxybutyrate-co-3-hydroxyvalerate) bioplastics reinforced and grafted with $\alpha$-cellulose fibers. Green Chem. 2015;17:4800-4814.

[35] Liang S, McDonald AG. Chemical and thermal characterization of potato peel waste and its fermentation residue as potential resources for biofuel and bioproducts production. J Agric Food Chem. 2014;62:8421-8429.

[36] Liang S, Han Y, Wei L, McDonald AG. Production and characterization of bio-oil and biochar from pyrolysis of potato peel wastes. Biomass Convers Biorefin. 2015;5:237-246.

[37] Lacoste J, Carlsson DJ, Falicki S, Wiles DM. Polyethylene hydroperoxide decomposition products. Polym Degrad Stab. 1991;34:309-323.

[38] Averett L, Griffiths P. Effective pathlength in attenuated total reflection spectroscopy. Anal Chem. 2008;80:3045-3049.

[39] Keen I, Raggatt L, Cool S, Nurcombe V, Fredericks P, Trau M, et al. Investigations into poly(3-hydroxybutyrate-co-3-hydroxyvalerate) surface properties causing delayed osteoblast growth. J Biomater Sci Polymer Edn. 2007;18:1101-1123.

[40] Wei L, McDonald AG. Thermophysical properties of bacterial poly(3-hydroxybutyrate): Characterized by TMA, DSC, and TMDSC. J Appl Polym Sci. 2015;132:42412, DOI: 10.1002/app.42412.

[41] Li Y, Pruitt C, Rios O, Wei L, Rock M, Keum JK, et al. Controlled Shape Memory Behavior of a Smectic Main-Chain Liquid Crystalline Elastomer. Macromolecules 2015;48:2864-2874.

[42] Bloembergen S, Holden DA, Hamer GK, Bluhm TL, Marchessault RH. Studies of composition and crystallinity of bacterial poly( $\beta$-hydroxybutyrate-co- $\beta$-hydroxyvalerate). Macromolecules. 1986;19:2865-2871.

[43] Yu H-Y, Qin Z-Y, Wang L-F, Zhou Z. Crystallization behavior and hydrophobic properties of biodegradable ethyl cellulose-g-poly(3-hydroxybutyrate-co-3-hydroxyvalerate): The influence of the side-chain length and grafting density. Carbohydr Polym 2012;87:2447-2454.

[44] Mitomo H, Watanabe Y, Ishigaki I, Saito T. Radiation-induced degradation of poly(3hydroxybutyrate) and the copolymer poly(3-hydroxybutyrate-co-3-hydroxyvalerate). Polym Degrad Stab. 1994;45:11-17.

[45] Bergmann A, Teßmar J, Owen A. Influence of electron irradiation on the crystallisation, molecular weight and mechanical properties of poly-(R)-3-hydroxybutyrate. J Mater Sci. 2007;42:3732-3738.

[46] Wei L, McDonald AG. Peroxide induced cross-linking by reactive melt processing of two biopolyesters: poly(3-hydroxybutyrate) and poly(L-lactic acid) to improve their melting processability. J Appl Polym Sci. 2015;132:41724, Doi: 10.1002/app.41724. 


\section{Figure Captions}

Fig. 1. Photodegradation reaction mechanisms of PHBV: (a) Norrish I, (b) Norrish II, (c) radical initiation, and (d) crosslinking.

Fig. 2. Light micrographs $(200 \times)$ of PHBV control (a) and after accelerated weathering for 500 h (b) and $1000 \mathrm{~h} \mathrm{(c).}$

Fig. 3. FTIR spectra of PHBV films unweathered control (a) and weathered for (b) $500 \mathrm{~h}$ and (c) $1000 \mathrm{~h}$.

Fig. 4. ${ }^{1} \mathrm{H}-\mathrm{NMR}$ spectra of PHBV that was (a) unweathered control and (b) weathered for $1000 \mathrm{~h}$.

Fig. 5. Crystallinity changes of PHBV with weathering (0-1000 h).

Fig. 6. PHBV $\mathrm{T}_{\mathrm{m}}$ and $\mathrm{T}_{\mathrm{g}}$ changes with exposure time $(0-1000 \mathrm{~h})$.

Fig. 7. Tensile property $(E, \varepsilon$, and $\sigma)$ changes of PHBV with exposure time (0-1000 h). 